\title{
International Interdisciplinary Consensus Meeting on the Evaluation of Developmental Dysplasia of the Hip
}

\section{Internationales interdisziplinares Konsensustreffen zur Evaluation der Diagnostik und Therapie der angeborenen Hüftdysplasie}

Authors

Joseph Gerard O’Beirne', Konstantinos Chlapoutakis², Sattar Alshryda ${ }^{3}$, Ustun Aydingoz ${ }^{4}$, Thomas Baumann ${ }^{5}$, Carolina Casini ${ }^{6}$, Maurizio de Pellegrin ${ }^{7}$, Gyula Domos ${ }^{8}$, Beat Dubs ${ }^{9}$, Sandeep Hemmadi ${ }^{10}$, Apostolos Karantanas ${ }^{11}$, Stylianos Kolovos ${ }^{12}$, Tanja Kraus ${ }^{13}$, Liang Zhao ${ }^{14}$, Claudia Maizen ${ }^{15}$, Mehrzad Mehdizadeh ${ }^{16}$, Daniel Molitorisz ${ }^{17}$, Thara Persaud ${ }^{18}$, Dimitrios Petratos ${ }^{19}$, Richard Placzek ${ }^{20}$, Sonja Placzek ${ }^{21}$, Sally Scott ${ }^{22}$, Raoul Schmid ${ }^{23}$, Ailbhe Tarrant ${ }^{24}$, Konstantinos Voulgaris ${ }^{25}$

\section{Affiliations}

1 Orthopaedics, University-Hospital Waterford, Ireland

2 Radiology, Vioapeikonisi Imaging Lab, Heraklion, Greece

3 Orthopaedics, Al Jalila Children's Specialty Hospital, Dubai, United Arab Emirates

4 Radiology, Hacettepe University School of Medicine, Ankara, Turkey

5 Paediatrics, Solothurn, Switzerland

6 Paediatrics, Azienda Ospedaliera Sant'Andrea, Roma, Italy

7 Orthopaedics, Ospedale San Raffaele, Milano, Italy

8 Orthopaedics, Semmelweis Egyetem, Budapest, Hungary

9 Internal Medicine, Qualimed Hungary Helathcare Services $\mathrm{Kft}$, Csoylospalos, Hungary

10 Orthopaedics, The Noah's Ark Children's Hospital for Wales, Cardiff, United Kingdom of Great Britain and Northern Ireland

11 Radiology, University of Crete School of Medicine, Heraklion, Greece

12 Orthopaedics, General Hospital Larissa, Thessaly, Greece

13 Orthopaedics, Medizinische Universität Graz, Austria

14 Orthopedic Surgery, LinYi Traditional Chinese Medicine Hospital, Lin'yi, China

15 Orthopaedics, Royal London Hospital, London, United Kingdom of Great Britain and Northern Ireland

16 Radiology, Tehran Medical University, Tehran, Iran (the Islamic Republic of)

17 Orthopaedics, Paediatric Trauma, Budapest, Hungary 18 Radiology, Children's Health at Tallaght, Dublin, Ireland 19 Orthopaedics, Mitera-Hospital, Athens, Greece

20 Clinic for Orthopaedics and Trauma Surgery, UniversityHospital Bonn, Germany

21 Orthopaedics, Medizinischer Dienst der Krankenversicherung Nordrhein, Düsseldorf, Germany

22 Radiology, Dorset-County-Hospital NHS Foundation Trust, Dorchester, United Kingdom of Great Britain and Northern Ireland

23 Paediatrics, Paediatrics, Baar, Switzerland

24 Radiology, Rotunda-Hospital, Dublin, Ireland

25 Radiology, Agios Therissos Medical Diagnostic Center, Nicosia, Cyprus
Key words

education, training, quality assurance, musculoskeletal

system, pediatrics

received 01.03.2019

accepted 14.05.2019

Bibliography

DOI https://doi.org/10.1055/a-0924-5491

Published online: June 13, 2019

Ultraschall in Med 2019; 40: 454-464

(c) Georg Thieme Verlag KG, Stuttgart · New York

ISSN 0172-4614

Correspondence

Prof. Joseph Gerard O’Beirne

Orthopaedics, University-Hospital Waterford, Dunmore Road, Waterford, X91 ER8E Waterford, Ireland

Tel.: ++ $353 / 51 / 848000$

Fax: $++353 / 51 / 842128$

jgobeirne@gmail.com

\section{ABSTRACT}

In September 2018, an international meeting of doctors of various disciplines, with expertise in the detection and treatment of DDH, was held in Csolyospalos, Hungary. The aim was to achieve consensus on the detection and early treatment of the condition and to develop a standardized system of teaching and training for hip ultrasound. There was strong agreement that US screening is essential. Specifically the Graf technique was selected as the technique of choice. Universal US screening was strongly favored. Screening should be carried out as soon as possible, but not later than the sixth week of age. US screening is cost-effective, does not result in overtreatment, and contributes to a reduction of long-term consequences. The essential principle of treatment is timely application of a device to achieve reduction, retention and maturation, by holding the hips in flexion, and a safe degree of abduction. It was agreed that the effectiveness of any screening policy depends on the correct scanning technique. Therefore, standardization of teaching and training of the 
Graf technique is mandatory. A unified teaching policy and materials should be developed for this purpose. Certification, re-certification and audit were discussed. The group, which has been formalized as the International Interdisciplinary Consensus Committee On DDH Evaluation (ICODE), will continue to meet and work towards establishing international consensus on DDH, standardizing and developing teaching and training of the Graf technique for hip US, and maintaining standards for detection and management.

\section{ZUSAMMENFASSUNG}

Im September 2018 fand in Csolyospalos, Ungarn, ein internationales Treffen von Fachärzten unterschiedlicher Disziplinen mit Expertise in der Diagnostik und Behandlung von DDH statt. Ziel war das Erreichen eines Konsenses zu den einzelnen Aspekten der DDH, die Entwicklung eines standardisierten Lehr- und Trainingssystems für die Anwendung von Hüftultraschall (US) sowie die Sicherung der Anwendungsqualität. Ein starker Konsens bestand darin, dass die klinische Untersuchung alleine unzureichend und eine Ultraschalluntersuchung unerlässlich ist. Die Methodik nach Graf wurde dabei als erste Wahl konsentiert. Ein möglichst vor der sechsten Lebenswoche durchgeführtes generelles US-Screening wurde stark favorisiert. Wesentliches Prinzip der US-gesteuerten Therapie ist dabei der möglichst frühe Behandlungsbeginn zur Reposition bzw. Retention und Nachreifung. Konsens bestand darin, dass die Effektivität eines Screenings stark von der korrekten Anwendung der Scan-Technik abhängt, weswegen eine standardisierte Ausbildung in der Methode nach Graf unerlässlich ist. Korrekt angewendet ist US kosteneffektiv, führt nicht zu Übertherapie und hilft, langfristige Folgen der DDH erheblich zu reduzieren. Daher sollen ein einheitlicher Lehrkatalog und Ausbildungsmaterialien entwickelt werden. Auch eine Zertifizierung, Re-Zertifizierung und mögliche Audits wurden eingehend diskutiert. Die Aufgabe des internationalen, interdisziplinaren Konsensuskomitees fur DDH Evaluation (ICODE) ist es, einen internationalen Konsens über Diagnostik- und Behandlungsstandards der DDH herzustellen sowie einen internationalen, standardisierten Lehr- und Ausbildungsplan in der Methodik nach Graf zu entwickeln und zu etablieren.

\section{Introduction}

Developmental dysplasia of the hip (DDH), formerly known as congenital dislocation of the hip $(\mathrm{CDH})$, is a condition that includes a wide spectrum of severity, which, if left untreated, may cause significant long-term complications (including intra-articular lesions in the pre-arthritic stage and early onset osteoarthritis [1, 2] thus leading to severe disability during early adult life.

Most cases of DDH, if diagnosed and treated early, are potentially reversible. All aspects of DDH have long been a source of debate, and universal agreement has not been reached. There is disagreement regarding the etiology and pathogenesis (genetic vs. mechanical), the preferred diagnostic approach (clinical vs. ultrasound (US)), the most effective screening policy (selective vs. universal) and the appropriate treatment approach.

Screening by US is well established as a critical element in the evaluation of the infant hip. However, there are many different techniques in use [3-6]. The value of US screening is dependent on adherence to correct technique which underlines the critical importance of standardized training, audit and quality control [7].

The aim of this meeting was to achieve consensus on all of the above-mentioned issues, to propose an evidence-based approach to the problem of DDH, and to develop a system for early detection, diagnosis and treatment.

\section{Meeting background}

The meeting was held in Csolyospalos, Hungary in September 2018. 24 medical doctors (radiologists, orthopedic surgeons, pediatricians, general practitioners), with expertise in DDH diagnosis and management, were invited to participate. Several countries were represented, including Austria, Cyprus, Germany, Greece, Hungary, Iran, Ireland, Italy, Switzerland, Turkey and the UK.
Participants prepared a summary of the current evidence on specific topics, which then served as the basis for discussion. Questionnaires about the most important points were then distributed to the participants, who had to vote either for or against the proposals.

Depending on the proportion of votes received, the strength of the recommendations was recorded as follows:

a) strong agreement supports the recommendation ( $\geq 90 \%$ )

b) general agreement supports the recommendation $(\geq 70 \%-<90 \%)$

c) general agreement weakly supports the recommendation $(\geq 50 \%-<70 \%)$

d) there is not enough evidence to support the recommendation $(<50 \%)$

Following the meeting, the moderators of each session provided a summary of their topics which is summarized in this paper, under the following headings:

- Terminology

- Etiology and pathogenesis

- Epidemiology and risk factors

- Detection of DDH

- US examination and techniques

- Timing of US screening

- Selective vs. universal US

- Treatment

- Training/auditing/accreditation

- Future plans

\section{Terminology}

The term "developmental dysplasia of the hip" (DDH) (dysplasia: Greek word meaning "abnormal growth or development of an 
organ or tissue") [8] has replaced congenital dislocation of the hip (CDH) (Klisic, 1984), [9]. There are two reasons for this: (a) it better describes the spectrum of pathology $[10,11]$, which ranges from simple immaturity to complete dislocation of the hip joint; (b) it introduces the term "developmental" (instead of "congenital”), implying that the disorder can develop even after birth.

Developmental dysplasia of the hip (DDH) is in fact a spectrum of disorders of the developing hip [12, 13], encompassing:

1. Hip abnormalities found on US and/or radiography without any clinical findings. Left untreated, these may present later as a frank dislocation.

2. Hip instability, such that the femoral head can be dislocated partially or fully from the acetabulum by an examiner, but relocates spontaneously.

3. Dislocated but reducible hip.

4. Dislocated hip that cannot be reduced.

\section{OUTCOME}

There was strong agreement in support of the use of the term "developmental dysplasia of the hip" (DDH) as the most appropriate term to describe the condition. (A)

\section{Etiology and Pathogenesis}

Many theories have been proposed to explain the etiology and mechanism of DDH.

Embryologically the femoral head is fully formed with a spherical configuration, a short neck and a primitive greater trochanter at 11 weeks [14]. With the subsequent development of the labrum, the femoral head is held centered in the acetabulum by the surface tension of the synovial fluid. Further interaction between the femoral head and the joint cartilage results in the normal development of the hip joint both antenatally and postnatally.

The etiology of DDH is thought to be multifactorial; a combination of genetic/constitutional [15] and mechanical factors [16, 17] is believed to be involved in the pathogenesis of the disorder.

The higher frequency of dislocations in females, familial/ethnic predisposition and geographical variation [18] support the genetic theory [19].

Abnormal forces transmitted to the femoral head, either before birth (breech presentation, left-sided predominance, etc.), at delivery (vaginal birth with breech presentation) or after birth (swaddling effect) constitute the basis of the mechanical theory $[14,19]$.

Regarding breech presentation, a study in 2010 [20] compared the incidence of DDH between breech twins (all with flexed hips and knees) and breech singletons (more of whom had flexed hips and extended knees); the breech singletons had a significantly higher incidence of DDH, supporting the specific importance of breech position with extended knees (frank breech).

\section{OUTCOME}

There was strong agreement that the etiology and pathogenesis of the disorder is multifactorial. (A)

\section{Epidemiology and risk factors}

Estimates of the incidence of DDH are highly variable [21]. This is mainly due to the wide variation in the definition of the disorder, the way it is diagnosed (clinical or imaging, US or X-ray, etc.) and the child's age at the time of the diagnosis $[22,23]$. The wide geographical variation of the disorder makes the situation even more complicated.

The incidence per 1000 live births ranges from 0.06 in Africans in Africa to 76.1 in Native Americans, with significant variability between and within racial groups and geographic location [24].

Based on the results of two relatively recent meta-analyses $[18,25]$, one of the most significant risk factors for DDH is breech presentation. Family history, female sex and maternal primiparity are also considered significant risk factors [26]. Other risk factors include ethnic background, co-existing lower limb or musculoskeletal deformities [27, 28], mechanical restriction before delivery (oligohydramnios, multiple pregnancies) or after birth (swaddling) [29].

The presence of risk factors alerts the clinician to the need to perform a thorough clinical and imaging examination. However, most of the DDH cases are diagnosed in babies without any identifiable risk factors. Therefore, DDH screening based solely on risk factor identification is not justified $[11,30]$.

\section{OUTCOME}

There was strong agreement that certain risk factors including breech presentation, female sex and family history are very important, with breech presentation being the most significant risk factor. (A)

\section{Detection of DDH}

Clinical examination of the newborn can detect hip instability but not acetabular dysplasia. The development of US has advanced our understanding of the normal development of the hip and allows monitoring of the dislocated, unstable and dysplastic hip [31-35].

Clinical examination is not sensitive enough to identify every child with DDH. The reported specificity is $90 \%$. The sensitivity, however, is reported as being as low as $50 \%$. US has been proved to be more sensitive and more specific for the diagnosis with significantly higher reported sensitivity and specificity (>90\%). The latter arguably is an underestimation, if we exclude sonographers who have not been properly trained [36-40].

Other imaging modalities (X-ray, CT, MRI) are not routinely used for the detection of DDH. X-ray, which has been the main- 
stay for imaging diagnosis in the past, has been effectively replaced by US, which offers earlier, radiation-free diagnosis.

Other imaging modalities may have a role in cases of late diagnosis of DDH or monitoring/guiding of therapy and/or maturation, when US is no longer feasible [41]. In the past arthrography was considered a gold standard for the evaluation of dislocated hips and for the identification of tissues between the femoral head and the acetabulum [42]. However, it provides indirect information on these structures. A study by Abril et al. [43] demonstrated significant concordance between US and arthrography. Therefore, while arthrography may have a role in the assessment and treatment of the late case (open/closed reduction) [44], the same information is provided more directly by US in the context of early diagnosis.

CT and MRI may be used to image the consequences of misdiagnosis later in the course of the disorder or for surgical planning [45].

\section{OUTCOME}

There was strong agreement that clinical examination alone is suboptimal for assessing children for the possibility of DDH. US assessment is essential. (A)

\section{US examination techniques}

The commonly known US techniques used worldwide are the Graf technique which is mainly used in Europe [3], the Terjesen technique [4] originating in Scandinavia (Terjesen et al, 1989), the Harcke technique developed in the United States [5] and the Suzuki technique developed in Japan [6]. A detailed description of the abovementioned techniques, is beyond the scope of this article.

A comparative literature review of these techniques was carried out via PubMed and seven papers were identified that compared two or more of these methods with each other.

Diaz A et al. [46] examined 208 babies (416 hips) with the Graf, Harcke and Suzuki techniques. Overall the three methods correlated well with regard to the severity of the pathology, but they found the Graf technique to be the most reliable.

Czubak et al. [47] compared the Graf and Terjesen techniques in 657 newborns (1312 hips) with a mean age of 23 days. The authors found that both techniques had similar results, but favored the Terjesen technique, as more specific and simpler. It is worth mentioning that in this study, 2 hips that were classified as Type III hips according to Graf, were classified as normal according to Terjesen.

Langford et al. [48] compared the Graf and Terjesen techniques and concluded that sonographers need to be trained in the Graf technique in order to get accurate results.

Falliner et al. [49] compared the Graf and Terjesen techniques in 232 neonates under 4 days old. In order to determine the reproducibility of the methods, 50 hips were evaluated by two skilled examiners. Statistical comparison showed a good correla- tion between the two techniques and proved no obvious difference in regard to inter-observer reliability. However, the Graf technique offered better reproducibility and intra-observer reliability.

Peterlein et al. [50] examined 207 newborns with both the Terjesen and Graf techniques and investigated the inter- and intra-observer reliability for the measurements of alpha angle, beta angle and femoral head coverage (FHC). They found better reliability for the alpha angle, followed by the beta angle and finally by the FHC, regardless of the experience level of the investigator.

Pacheco et al. [51] investigated 225 infants at a mean age of 7.79 weeks with the Graf, Harcke and Terjesen techniques and calculated the specificity and sensitivity for each. They found the Graf technique to be the most sensitive and specific, and proved that the alpha angle was the most reliable criterion on which to base a treatment decision.

Kotlarsky et al. [52] published a review article in 2015, comparing the Graf, Suzuki and Harcke techniques. Their conclusion was that the Graf technique fulfilled the requirements for an effective US technique, offering simple, precise, quantitative and consistent definitions for examination and diagnosis.

Comparative presentation of the results of the abovementioned studies are presented in $>$ Table 1.

In summary, our literature review strongly suggests that the Graf technique seems to be superior to the other techniques. A recent review has also reinforced this position [53].

The Graf technique correlates the pathology and severity of acetabular dysplasia, with the patient's age, thus offering a patient-specific diagnostic and treatment algorithm [7]. The scanning technique per se is standardized, and its application and principles have been thoroughly described [54]. The value of structured training by authorized teachers has been recognized [55]. Mistakes may be avoided by strict adherence to the technique, so only appropriately trained and certified sonographers should be allowed to scan. Continuous quality control and audit should also be offered [7].

The technical details of the technique were also thoroughly discussed during the meeting. Adoption of the scanning principles (including equipment, technique and documentation) as presented in detail in the teaching manual [54] is mandatory.

\section{OUTCOME}

There was strong agreement that the preferred US examination technique, for the early detection and treatment of $\mathrm{DDH}$, is the Graf technique. Strict adherence to the principles of the technique, as presented in the teaching manual, is mandatory. (A)

\section{Timing of US screening}

Several papers make the point that closed treatment of DDH is more successful if instituted earlier [56-59]. From this, the view 
- Table 1 Studies comparing different US techniques.

\begin{tabular}{|l|l|l|l|l|}
\hline article & reliability & sens/specif & interobserver & intraobserver \\
\hline $\begin{array}{l}\text { Diaz A et al. (1994) - Compares Graf } \\
\text { vs. Harcke vs. Suzuki }\end{array}$ & graf & - & - & - \\
\hline $\begin{array}{l}\text { Czubak et al. (1998) - Compares Graf } \\
\text { vs. Terjesen }\end{array}$ & equal & terjesen & terjesen & - \\
\hline $\begin{array}{l}\text { Langford et al. (2001) - compares Graf } \\
\text { vs. Terjesen }\end{array}$ & $\begin{array}{l}\text { graf (needs } \\
\text { more ex- } \\
\text { perience) }\end{array}$ & - & - & - \\
\hline $\begin{array}{l}\text { Falliner et al. (2006) - compares Graf } \\
\text { vs. Terjesen }\end{array}$ & equal & graf & equal (except for & graf \\
\hline $\begin{array}{l}\text { Peterlein et al. (201) - compares Graf } \\
\text { vs. Terjesen }\end{array}$ & graf & - & - & - \\
\hline $\begin{array}{l}\text { Pacheco et al. (2012) - compares Graf } \\
\text { vs. Terjesen vs. Harcke }\end{array}$ & graf & graf & graf \\
\hline $\begin{array}{l}\text { Kotiarsky et al. (2015) - compares } \\
\text { Graf vs. Suzuki vs. Harcke }\end{array}$ & graf & graf & - & graf \\
\hline
\end{tabular}

may be taken that the earlier the scan is carried out and any necessary treatment is begun, the better.

On the other hand, some authors have expressed concern regarding overdiagnosis arising from scanning occurring very early $[23,60]$. In the German language literature, Grill and Muller [61] similarly expressed concern about overdiagnosis, when scans are performed in the first week.

There is a range of recommendations in the literature regarding the time to scan. The German language literature generally recommends scanning before six weeks of age [62-65]. There is quite a variation in the English language literature. Tyagi et al. [66] described scanning at an average of 5 weeks. Bacche et al. [67], Imrie et al. [68] and Clarke et al. [27], all described scanning at 6 weeks. Kolb et al. [69] and Schaeffer et al. [70], both recommended scanning at 6 to 8 weeks. Choudry et al. [71] recommended scanning babies with unilateral limitation of abduction at 8 weeks. Pillai et al. [72] reported that the specificity and accuracy of US with the Graf technique was at its highest at 3 months of age.

Some authors have made a distinction between babies who have clinical signs of instability and those who are being screened without any clinical abnormality $[27,73]$.

To summarize, the picture which emerges is that earlier diagnosis facilitates earlier treatment, which is more successful, but it has been suggested that scanning too early can risk overtreatment, as many hips which appear immature at first will mature later. There is support for early scanning in babies with clinical signs. Otherwise, in the German language literature, the recommendation is to scan before six weeks of age, while in the English language literature, the range of recommended ages for scanning babies without clinical signs goes from just under six weeks to three months.

At this meeting, it was pointed out that the standard practice in Austria is to scan the baby's hips twice: first at birth and then again between the $4^{\text {th }}$ and $7^{\text {th }}$ week of life. This allows treatment to begin as soon as possible, and therefore more successfully.
However, even if dysplasia is only detected on the second scan, between the $4^{\text {th }}$ and $7^{\text {th }}$ week, the hip is still within the maturation curve. There was strong support for the view that, given the maturation process of the hip, the earlier a problem is identified and treated the better. It should be possible for a trained examiner to distinguish between clearly abnormal hips and those which may simply be immature and can be followed up, thus avoiding the danger of overtreatment.

\section{OUTCOME}

There was strong agreement at this meeting that US screening should be carried out as soon as possible, but no later than the sixth week of life. (A)

\section{Selective vs. universal US screening}

The literature surrounding this question is very varied. To some extent, it reflects an evolution of understanding over time, but also variation in practice between different countries.

There have been some reviews that cast doubt upon the whole practice of US screening [11, 74 - 76]. A Cochrane review [75, 76] concluded that neither US strategy had been demonstrated to improve clinical outcomes, including late diagnosed DDH and surgery. A Canadian review in 2001 [74] concluded there was "fair evidence" to exclude both "general US screening" and "selective screening". Shipman et al. [11], based in the USA, carried out a meta-analysis, in which they were critical of the literature on screening and interventions for DDH.

Leaving these criticisms of the evidence in the literature aside, the debate about universal vs. selective screening revolves to a large extent around effectiveness, cost, and the possibility of overdiagnosis and overtreatment. 
Several papers have claimed good results with a regime of selective US screening [27, 77 - 80]. In a Norwegian study, Holen et al. [77] argued based on their findings that "when clinical screening is of high quality", universal US was not necessary. Instead they favored selective screening based on clinical findings and risk factors. Mahan et al. [78] in the USA described an analytic model and they argued that the best approach was to clinically screen all neonates and then to use US selectively for infants at high risk. Laborie et al. [79] from Norway referred to a regime of selective screening resulting in an "acceptable" rate of early treatment and low rates of subluxated/dislocated hips. In an Australian study Leba et al. [80] highlighted the cost of screening but showed good results from selective screening. Clarke et al. [27] in the UK also showed good results using a system of selective screening based on breech presentation, family history and foot deformity.

However, there have been a number of studies pointing to patients with $\mathrm{DDH}$ who would have been missed by a selective US screening regime [67, 81, 82]. A review in the USA [82] looked at skeletally mature patients who had had surgery for the late consequences of DDH. $85.3 \%$ of them would not have been screened in a selective US screening program.

Starting in the early $1990 \mathrm{~s}$, evidence of the potential of universal US screening began to be published in the English language $[83,84]$ and since then a number of papers reinforcing this have been published [56, 69, 85-88]. In 2004 Wirth et al. [85] from Germany reported that a program of "general" US screening had resulted in a dramatic decrease in surgical procedures, hospitalizations and late presentation. Tschauner et al. [56] from Austria reported that a cohort of babies who had come through a universal screening program had a $98.9 \%$ success rate with treatment. A year later, vonKries et al. [86] from Germany reported a reduction in the rate of operative procedures due to "general" US screening, but cautioned that further assessment was required to balance this benefit against potential overtreatment and adverse effects. Reporting on the outcomes of the Austrian universal screening program, Thalinger et al. [87] showed a significant decrease in the rates of open reduction, pelvic surgery, and hospital admissions for DDH. Kolb et al. [69], also from Austria, observed that risk factors had a low impact within their group. Therefore, they were also in favor of universal screening. Guler et al. [88] from Turkey reported on their population of babies who underwent US screening with satisfactory results and thus recommended its use.

At this meeting, a speaker from Ireland described how a system of US screening for DDH had been initiated over the previous four years, starting from a highly variable situation in the country. A system of selective US screening was now almost in place. At this time, resources were not available for universal screening. However, an added dimension in Ireland was an extremely litigious climate, in which other health service screening programs had been subjected to legal action because of false negatives. This meant that caution was necessary in initiating any screening program, while making sure the objectives were realistic and clearly communicated.

The Swis team presented the design and application of a nationwide universal screening program, which was introduced under the name "The Mongolian Project" [89-91]. The project, which included more than 300000 scans and over 4000 successfully treated children, was commended as a very worthy and successful initiative. It was seen as a good example of how a universal screening, early-scan and early-treatment national policy can be successfully implemented nationwide, even when healthcare resources are scarce.

A presenter from Austria described how universal US screening had been established in that country since 1992, and had been shown to be successful and cost-effective. Universal US screening has been in place in Germany since 1996. The German language literature supports this position, in terms of reduced late diagnosis and reduced rates of late surgery related to dysplasia [61, 63, 92].

One of the presenters at this meeting, having practiced both in Austria and in the UK, reported on the striking contrast between the two systems. In the UK, where selective rather than universal US screening is employed, there is an incidence of late diagnosis of DDH which is almost unknown in Austria. Over a four-year period, one pediatric center in the UK had 114 patients requiring operations for DDH. 91 of these were late presentations (63 with no risk factors). 62 patients had open surgery, and 52 had closed reduction and spica application, with 8 subsequently requiring open surgery. It was stated that there appeared to be resistance in a system employing selective screening to moving to universal screening despite the evidence, probably largely due to issues regarding logistics and resources.

One issue for debate is whether the benefits of universal US screening justify the cost. Paton et al. [93] from the UK called its value into question, suggesting that it could not be justified on the grounds of cost. However, Clegg et al. [84], also from the UK, showed as far back as 1999 that the cost appeared justified in terms of the treatment savings. Further UK studies [84, 95] suggested that universal screening did not incur increased costs. More recently, Thaler et al. [96] from Austria demonstrated that the cost of a universal US screening program was more than offset by the costs of surgical and non-surgical treatments that had been avoided, and that therefore the policy was indeed cost-effective. The German language literature supports this position. Ihme et al. [92] compared the costs of hip surgery due to DDH at two different time periods (patients who received US and a historical group) and demonstrated that the costs of hip US were lower than the costs of hip surgery. This position was further supported by the study by Farr [65].

At this meeting, the presenters expressed the view that a policy of universal US screening is indeed cost-effective, citing the studies by Clegg et al. [84] and Thaler et al. [96]. This is true, particularly when we include the prospective costs, including late surgery which is avoided by early diagnosis and treatment. The difficulty is in making the case for the initial investment, based on the expectation of overall cost savings in the longer term.

Another concern which has been expressed is the possibility of overdiagnosis and overtreatment, with the associated risk of avascular necrosis [29, 60,66]. Most notably, in their guidelines published in 2016, the American Academy of Pediatrics [29] recommended against universal US screening in North America, citing "expense, inconvenience, inconsistency, subjectivity, and high false-positive rates". 
However, the point has been made that a universal US screening system can actually reduce the non-operative treatment rate since treatment is based on objective rather than subjective clinical criteria [97, 98].

At this meeting, the prevailing view was the latter, i. e. that the objectivity provided by US screening that is carried out and interpreted correctly, should not result in babies being treated unnecessarily. However, some attendees observed that in a system in which babies are treated according to US findings at an early age, overtreatment might happen.

Another area of expressed uncertainty concerns later outcomes of babies with hip dysplasia [56, 99]. Thalinger et al. [87], reporting on the late outcomes of the Austrian screening program, did show a decrease in the frequency of late pelvic osteotomy arising from hip dysplasia.

At this meeting, there was strong agreement that a system of universal US screening results in a reduction in the need for later pelvic osteotomies, quoting in particular the findings of Grill and Muller [61] and Thalinger et al. [87].

In summary, while the German language literature is supportive of universal US screening, the English language literature presents a mixed picture. To a large extent this is reflective of geographical variation. It is clear that universal US screening results in a low rate of late diagnosis. What varies between studies is the extent to which this approach outperforms selective screening, and whether this extra benefit is offset by cost, or the possibility of overdiagnosis and overtreatment, with its attendant risk. Some believe that the degree to which this lowered rate of late diagnosis translates into a reduction of the sequelae of dysplasia at skeletal maturity also remains to be established.

At this meeting it was stated that this variation in findings reported in the literature was probably due to studies not being comparable. Techniques could vary, the scans could be carried out by individuals with varying levels of training, the definition of "risk factors" could vary, the quality of clinical screening could vary and different outcome measures may have been used.

In addition, the definition of "cost" could vary depending on what factors were included. The consensus group emphasized two points:

Firstly, there should be a differentiation between clinical effectiveness and cost-effectiveness. The former is what healthcare providers should aim to practice and must be the gold standard, whereas the latter (cost-effectiveness) is a compromise and should be honestly explained to parents and to the public.

Secondly, all studies that assessed cost-effectiveness compared the cost of a universal screening program to the cost of surgical treatment for DDH. None of the studies included long-term effects such as quality of life, the need for future hip replacement, and loss of the ability to work. The published German, Austrian, Swiss and Coventry studies demonstrated that although there is a marginal increase in the universal screening cost, it is a good value for the money.

Reference was made to a recent report by Biedermann and Eastwood [98] from Austria and the UK, respectively. This was a joint review calling for a "paradigm shift" towards universal US screening, stating that it results in the lowest late presentation rates, low treatment rates, a lower rate of surgery on the infant hip, and a reduction in the rate of surgery for DDH in later life. They also make the point that avascular necrosis can be avoided, and that modern orthoses should have a zero rate of AVN. The dominant outcome of the discussion was one of support for this "paradigm shift".

\section{OUTCOME}

There was strong agreement in favor of universal US screening. (A)

There was strong agreement that, when all short- and longterm costs are taken into account, a system of universal US screening is cost-effective. (A)

There was general agreement that a system of universal US screening using the Graf technique would not result in overtreatment. (B)

There was strong agreement that a system of universal US screening using the Graf technique will result in a reduction of later problems with dysplasia. (A)

\section{Treatment}

According to the classification system developed by Graf [41, 54], Type I hips are mature hips, so they do not require any treatment. Type lla hips are immature hips and as long as their degree of maturity is age-appropriate, treatment is not required. However, they should reach maturity by three months of age. Otherwise, they are re-classified as Type IIb and require treatment. Treatment is required for any hip that is classified as Type lla minus or worse. Therefore, Type IIC, D, III \& IV hips always require treatment. - Table 2 summarizes the abovementioned classification/treatment scheme.

DDH treatment according to Graf consists of (a) femoral head reduction, (b) maintenance of head relocation (retention) and (c) correction of any residual acetabular dysplasia (maturation).

Early initiation of treatment is strongly recommended as a substantial part of maturation of the hip joint occurs within the first three months. By six weeks, the baby's hip is already half-way along this steep part of the maturation curve. Therefore, it is very important for treatment to be initiated before six weeks of age. Correct use of an abduction device is the mainstay of treatment. A combination of flexion $\left(110^{\circ}\right)$ and abduction $\left(45^{\circ}\right)$ prevents avascular necrosis of the femoral head, as this position avoids excessive pressure on the femoral head against the hyaline cartilage of the acetabulum.

The essential elements of early treatment are:

a) Reduction: This is required in Types D, III and IV. Provided treatment is initiated early enough, this should be achieved by the position of flexion and a safe degree of abduction as has been described above. Treatment position may be reached by a spica cast, although in newborns some centers prefer the use of an external harness.

b) Retention: This is required in Type Ilc unstable and in Type D, III and IV hips that have been effectively reduced. Retention is 
- Table 2 Treatment of DDH according to Graf's hip classification.

\begin{tabular}{|c|c|c|c|}
\hline hip type & age & type Description & treatment \\
\hline I & any age & mature hip & not required \\
\hline Ila & $<6$ weeks & immature hip & US follow-up \\
\hline $\mathrm{Ila}(+)$ & $6-12$ weeks & immature hip & $\begin{array}{l}\text { not required/ } \\
\text { optional follow-up }\end{array}$ \\
\hline $\operatorname{lla}(-)$ & $6-12$ weeks & $\begin{array}{l}\text { delayed } \\
\text { ossification }\end{array}$ & \multirow[t]{4}{*}{$\begin{array}{l}\text { treatment is } \\
\text { recommended }\end{array}$} \\
\hline Ilb & $>12$ weeks & dysplastic hip & \\
\hline IIC & any age & $\begin{array}{l}\text { heavily dysplastic } \\
\text { hip }\end{array}$ & \\
\hline D, III, IV & any age & Decentered hip & \\
\hline
\end{tabular}

achieved by an external device, again combining flexion with a safe degree of abduction.

c) Maturation: This is required in Type Ila minus, Type IIb, Type Ilc stable, and in hips of more severe grades, which have been reduced if necessary, and retained as above. An external device maintains the hip in flexion and a safe degree of abduction.

Treatment should be continued until the hip reaches Graf Type I.

There are a number of specific varieties of splints and harnesses available for treatment. The reported success rate is variable but for the most part is in excess of $90 \%$ [90, $100-103]$. The likely reasons for the reported variation are the selection of the threshold for treatment, the variable length of treatment, the variable age of the children when treatment begins and the different definitions of failure by the reporting authors.

At this meeting, no recommendation was made for any specific device. Rather the important point was the position of the hips during treatment.

The underlying principle of the favored treatment approach is to start treatment early. If the femoral head does not relocate by closed means, as may happen particularly in older babies, open reduction may be required. In older children with centered hips but residual dysplasia, pelvic osteotomy may become necessary. However, these issues are outside the scope of this meeting, which was focused on closed treatment facilitated by early diagnosis.

\section{OUTCOME}

There was strong agreement that the important principle of treatment is the application of a device placing the hips in the appropriate degrees of flexion and abduction. The type of device is less important than early and accurate diagnosis and early initiation of treatment. (A)

\section{Training, auditing, accreditation}

It was recognized at this meeting that teaching of the Graf technique must be standardized. Who is trained will vary from country to country, but at a minimum, it must be a health care professional. In order to help with this standardization, a set of slides was prepared and presented. They summarize the theoretical content of the basic course. Future work on these will include further refinement of the slides and translation into languages other than English.

Regarding future development of the course, there was support for including a section on the basic physics of US and for making the theory of the course available online prior to attendance.

Practical sessions should include all theoretical and practical aspects of the technique, including scanning demonstration on a phantom and/or babies.

The ideal duration of the course should be two days.

Regarding further training, it was agreed that the update/accreditation course should only be taken by those who have done the basic course, normally at least six months previously. This course should also be standardized. Further issues, to be addressed at future meetings, include required practical training and experience following the basic course, accreditation of instructors, and re-accreditation.

Another area for future development will be the formation of national committees whose roles would include approval of training courses, examiners and instructors, re-accreditation of examiners and instructors, and quality management. Such committees would in turn connect with the international organization (ICODE - the International Interdisciplinary Consensus Committee on DDH Evaluation).

\section{OUTCOME}

There was strong agreement on the following points (A): US examiners should at a minimum be health care professionals. The training courses should be standardized. Further development of the courses is desirable.

Candidates for the update/accreditation course should have first completed the basic course, normally at least six months prior.

\section{Future plans}

The group has now been formalized as the International Interdisciplinary Consensus Committee on DDH Evaluation (ICODE). The objectives of the group are:

- To work towards consensus on the various issues regarding $\mathrm{DDH}$, in particular policies for detection and early treatment.

- To promote, standardize and continually improve teaching and training in the Graf technique of infant hip US.

- To use its international network to support research, audit and quality improvement in the field of detection and early treatment of $\mathrm{DDH}$. 
An ICODE website has been set up and is being developed. It can be accessed via www.icode.expert

The group will continue to meet, with the next meeting scheduled for Heraklion, Crete, in May/June 2019. As it develops, the group will aim to widen its efforts internationally with the goal of achieving the best possible outcomes from DDH worldwide.

\section{Conflict of Interest}

The authors declare that they have no conflict of interest.

\section{References}

[1] Fujii M, Nakashima $Y$, jingushi $S$ et al. Intraarticular findings in symptomatic developmental dysplasia of the hip. J Pediatr Orthop 2009; 29: 9-13

[2] Reijman M, Hazes J, Pols $\mathrm{H}$ et al. Acetabular dysplasia predicts incident osteoarthritis of the hip: the Rotterdam study. Arthritis Rheum 2005; 52 : $787-793$

[3] Graf R. The diagnosis of congenital hip joint dislocation by ultrasound compound treatment. Arch Orthop Trauma Surg 1980; 97: 117-133

[4] Terjesen T, Bredland T, Berg V. Ultrasound for hip assessment in the newborn. J Bone Joint Surg [Br] 1989; 71-B: 767-773

[5] Morin C, Harcke H, MacEwen G. The infant hip: real time US assessment of acetabular development. Radiology 1985; 157: 673-677

[6] Suzuki S, Kasahara Y, Futami T et al. Ultrasonography in congenital dislocation of the hip: simultaneous imaging of both hips from in front. Bone Joint Surg 1991; 73-B: 879-883

[7] Graf R. Hip sonography: background; technique and common mistakes; result; debate and politics; challenges. Hip Int 2017; 27: 215-219

[8] Oxford Living Dictionaries. Oxford Living Dictionaries. [Internet]. Available from: https://en.oxforddictionaries.com/definition/dysplasia

[9] American Academy of Orthopedic Surgeons (AAOS). Advisory Statement. "CDH" should be "DDH". 1991

[10] Dezateux C, Rosendahl K. Developmental dysplasia of the hip. Lancet 2007; 369: 1541 - 1552

[11] Shipman S, Helfand M, Moyer $V$ et al. Screening for developmental dysplasia of the hip: A systematic literature review for the U.S. Preventive Services Task Force. Pediatrics 2006; 117: e557-e576

[12] Alshryda S, Jones S, Banaszkiewicz P. Postgraduate Paediatric Orthopaedics: The Candidate's Guide to the FRCS (Tr and Orth) Examination. Cambridge: Cambridge University Press. 2014

[13] Herring J. Tachdjian's Pediatric Orthopaedics: From the Texas Scottish Rite Hospital for Children. 5th ed Philadelphia: Saunders Elsevier; 2013

[14] Koureas G, Wicart P. Etiology of Developmental Hip Dysplasia or Dislocation. Hip International 2007; 17 (Suppl. 5): S1-S7

[15] Carter C, Wilkinson J. Genetic and environmental factors in the etiology of congenital dislocation of the hip. Clin Orthop Relat Res 1964; 33 : $119-128$

[16] Browne D. Congenital deformities of mechanical origin. Arch Dis Child 1955; 30: $37-41$

[17] Dunn P. Perinatal observations on the etiology of C.D.H. Clin Orthop 1976; 119: 11-22

[18] Ortiz-Neira C, Paolucci E, Donnon T. A meta-analysis of common risk factors associated with the diagnosis of developmental dysplasia of the hip in newborns. European Journal of Radiology 2012; 81: e344-e351

[19] Seringe R, Bonnet J, Katti E. Pathogeny and natural history of congenital dislocation of the hip. Orthopaedics \& Traumatology: Surgery \& Research 2014; 100: 59-67
[20] De Pellegrin M, Moharamzadeh D. Developmental dysplasia of the hip in twins: the importance of mechanical factors in the etiology of DDH. J Pediatr Orthop 2010; 30: 774-778

[21] MacFarlane A. Congenital dislocation of the hip - an epidemiological conundrum. Maternal and Child Health Journal 1980; 5: 13-15

[22] Lehmann H, Hinton R, Morello P et al. Developmental dysplasia of the hip practice guideline: technical report. Committee on Quality Improvement, and Subcommittee on Developmental Dysplasia of the Hip. Pediatrics 2000; 105: E57

[23] Bialik V, Bialik G, Blazer S et al. Developmental dysplasia of the hip: a new approach to incidence. Pediatrics 1999; 103: 93 - 99

[24] Loder R, Skopelja E. The epidemiology and demographics of hip dysplasia. ISRN Orthop 2011; 2011: 238607

[25] De Hundt M, Vlemmix F, Bais J et al. Risk factors for developmental dysplasia of the hip: a meta-analysis. European Journal of Obstetrics \& Gynaecology and Reproductive Biology 2012; 165: 8-17

[26] Paton R, Hinduja K, Thomas C. The significance of at-risk factors in ultrasound surveillance of developmental dysplasia of the hip. J Bone Joint Surg [Br] 2005; 87-B: 1264-1266

[27] Clarke N, Reading I, Corbin C et al. Twenty years experience of selective secondary ultrasound screening for congenital dislocation of the hip. Arch Dis Child 2012; 97: 423-429

[28] Perry D, Tawfik S, Roche A et al. The association between clubfoot and developmental dysplasia of the hip. J Bone Joint Surg [Br] 2010; 92-B: $1586-1588$

[29] Shaw B, Segal L. Evaluation and referral for developmental dysplasia of the hip in infants. Pediatrics 2016; 138: e20163107

[30] Standing Medical Advisory Committee. Screening for the detection of congenital dislocation of the hip. Arch Dis Child 1986; 61: 921-926

[31] Graf R. Classification of hip joint dysplasia by means of sonography. Arch Orthop Trauma Surg 1984; 102: 248-255

[32] Clarke N, Harcke H, McHugh P et al. Real-time ultrasound in the diagnosis of congenital dislocation and dysplasia of the hip. J Bone Joint Surg [Br] 1985; 67: 406-412

[33] Wood M, Conboy V, Benson M. Does early treatment by abduction splintage improve the development of dysplastic but stable neonata hips? J Pediatr Orthop 2000; 20: 302-305

[34] Engesaeter L, Wilson D, Nag D et al. Ultrasound and congenital dislocation of the hip. The importance of dynamic assessment. J Bone Joint Surg [Br] 1990; 72: 197-201

[35] Gardiner H, Dunn P. Controlled trial of immediate splinting versus ultrasonographic surveillance in congenitally dislocatable hips. Lancet 1990; 336: $1553-1556$

[36] Alshryda S, Huntley J, Banaszkiewicz P. Paediatric Orthopaedics: An Evidence-Based Approach to Clinical Questions. Springer International Publishing. 2017

[37] Paton R, Srinivasan M, Shah B et al. Ultrasound screening for hips at risk in developmental dysplasia. Is it worth it? J Bone Joint Surg [Br] 1999; 81: 255-258

[38] Paton R, Choudry Q. Neonatal foot deformities and their relationship to developmental dysplasia of the hip: an 11-year prospective, longitudinal observational study. J Bone Joint Surg [Br] 2009; 91: 655-658

[39] Paton R. Screening for hip abnormality in the neonate. Early Hum Dev 2005; 81: 803-806

[40] Jari S, Paton R, Srinivasan M. Unilateral limitation of abduction of the hip. A valuable clinical sign for DDH? J Bone Joint Surg [Br] 2002; 84: 104107

[41] Graf R. Hip Sonography. 2nd ed. Berlin Heidelberg: Springer-Verlag; 2006

[42] Fleissner P, Ciccarelli C, Eilert R et al. The success of closed reduction in the treatment of complex developmental dislocation of the hip. J Pediatr Orthop 1994; 14: 631-635 
[43] Abril ], Berjano P, Díaz A. Concordance between hip ultrasonography and hip arthrography in the assessment of developmental dysplasia of the hip. J Pediatr Orthop B 1999; 8: 264-267

[44] Placzek R, Funk J, Druschel C. Congenital hip dysplasia in newborns: Clinical and ultrasound examination, arthrography and closed reduction. Oper Orthop Traumatol 2013; 25: 417-429

[45] Starr V, Ha B. Imaging Update on Developmental Dysplasia of the Hip With the Role of MRI. Am J Roengenol 2014; 203: 1324-1335

[46] Diaz A, Cuervo M, Epeldegui T. Simultaneous Ultrasound Studies of Developmental Dysplasia of the Hip Using the Graf, Harcke, and Suzuki Approaches. Journal of Pediatric Orthopaedics B 1994; 3: 185-189

[47] Czubak J, Kotwicki T, Ponitek T et al. Ultrasound measurements of the newborn hip. Comparison of two methods in 657 newborns. Acta Orthop Scand 1998; 69: 21-24

[48] Langford S, New S, Patel K. Comparison of Two Techniques Used in the Assessment/Measurement of Developmental Dysplasia of the Hip (DDH). Ultrasound 2001; 9: 26-30

[49] Falliner A, Schwinzer D, Hahne $\mathrm{H}$ et al. Comparing ultrasound measurements of neonatal hips using the methods of Graf and Terjesen. J Bone Joint Surg [Br] 2006; 88: 104-106

[50] Peterlein C, Schüttler K, Lakemeier S et al. Reproducibility of different screening classifications in ultrasonography of the newborn hip. BMC Pediatr 2010; 10: 98

[51] Pacheco E, Bronzatto E, Martins G et al. EPOS - European Society of Radiology [Internet]. 2012. doi:http://dx.doi.org/10.1594/ecr2012/ C-2049

[52] Kotlarsky P, Haber R, Bialik V et al. Developmental dysplasia of the hip: What has changed in the last 20 years? World Journal of Orthopedics 2015; 6: 886 - 901

[53] Chlapoutakis K, Kolovos S, Casini C. Ultrasonography in developmental dysplasia of the hip: a review of current clinical strategies and recommendations for revision of practice. Hellenic Journal of Radiology 2017; 2: $36-46$

[54] Graf R, Lercher K, Scott S et al. Essentials of Infant Hip Sonopgraphy according to Graf. Stolzalpe Sonocenter. 2017

[55] Shirai $Y$, Wakabayashi K, Wada I et al. Reproducibility of acquiring ultrasonographic hip images by the Graf method after an infant hip ultrasound training course. J Med Ultrason 2018; 45: 583-589

[56] Tschauner C, Fürntrath F, Saba Y et al. Developmental dysplasia of the hip: impact of sonographic newborn hip screening on the outcome of early treated decentered hip joints-a single center retrospective comparative cohort study based on Graf's method of hip ultrasonography. J Child Orthop 2011; 5: 415-424

[57] Price K, Dove R, Hunter J. Current screening recommendations for developmental dysplasia of the hip may lead to an increase in open reduction. Bone Joint J 2013; 95-B: 846-850

[58] Omeroglu H, Kose N, Akceylan A. Success of Pavlik harness treatment decreases in patients $\geq 4$ months and in ultrasonographically dislocated hips in developmental dysplasia of the hip. Clin Orthop Relat Res 2016; 474: $1146-1152$

[59] Phelan N, Thoren J, Fox C et al. Developmental dysplasia of the hip: incidence and treatment outcomes in the Southeast of Ireland. Irish Journal of Medical Science 2015; 184: 411-415

[60] Roovers E, Boere-Boonekamp M, Castelein R et al. Effectiveness of ultrasound screening for developmental dyplasia of the hip. Arch Dis Child Fetal Neonatal Ed 2005; 90: F25 - F30

[61] Grill F, Müller D. Ergebnisse des Hüftultraschall-Screenings in Österreich. Orthopäde 1997; 26: 25-32

[62] Graf R. Hüftsonografie - ein update. Orthopäde 2002; 31: 181 - 189

[63] Schilt M. Optimaler Zeitpunkt des Hüftsonografie-Screenings. Ultraschall in Med 2001; 22: 39-47
[64] Schilt M. Die Hüftsonografie nach Graf bei Neugeborenen und Säuglingen. Schweiz Med Forum 2008; 8: 942-945

[65] Farr S. Wann ist der optimale Zeitpunkt für ein sonografisches Hüftscreening? Orthopäde 2008; 37: 532-540

[66] Tyagi R, Zgoda M, Short R. Targeted screening of hlp dysplasia in newborns: experience at a district general hospital in Scotland. Orthop Rev (Pavia) 2016; 8: 6640

[67] Bache C, Clegg J, Herron M. Risk factors for developmental dysplasia of the hip in the neonatal period. Journal of Pediatric Orthopaedics 2002; 11: $212-221$

[68] Imrie M, Scott V, Stearns P et al. Is ultrasound screening for DDH in babies born breech sufficient? J Child Orthop 2010; 4: 3-8

[69] Kolb A, Schweiger N, Mailath-Pokomy M et al. Low incidence of early developmental dysplasia in universal ultrasonographic screening of newborns: analysis and evaluation of risk factors. Int Orthop 2016; 40: $123-127$

[70] Schaeffer E, Mulpuri K. Developmental dysplasia of the hip: addressing evidence gaps with a multicentre prospective international study. Med Aust 2018; 208: 359-364

[71] Choudry Q, Goyal R, Paton R. Is limitation of hip abduction a useful clinical sign in the diagnosis of developmental dysplasia of the hip? Arch Dis Child 2013; 98: 862-866

[72] Pillai A, Joseph J, McAuley A et al. Diagnostic accuracy of static Graf technique of ultrasound evaluation of infant hips for developmental dysplasia. Arch Orthop Trauma Surg 2001; 131: $53-58$

[73] American Academy of Orthopaedic Surgeons (AAOS). Guideline Central. [Internet]. 2014. doi:https://www.aaos.org/research/guidelines/ ddhguidelinefinal.pdf

[74] Patel H. Preventative health care, 2001 update: screening and management of developmental dysplasia of the hip in newborns. CMAJ 2001; 164: $1669-1677$

[75] Shorter D, Hong T, Osborn D. Screening programmes for developmental dysplasia of the hip in newborn infants. Cochrane Database of Systematic Reviews 2011; 9: CD004595

[76] Shorter D, Hong T, Osborn D. Health CrSpfddothiniEBC, 11-54 8. Cochrane review: Screening programmes for developmental dysplasia of the hip in newborn infants. Evid Based Child Health 2013; 8: 11-54

[77] Holen K, Tegnander A, Bredland T et al. Universal or selective screening of the neonatal hip using ultrasound? Bone \& Joint Journal 2002; 84: $886-890$

[78] Mahan S, Katz J, Kim Y. To screen or not to screen? A decision analysis of the utility of screening for developmental dysplasia of the hip. J Bone Joint Surg [Am] 2009; 91-A: 1705-1719

[79] Laborie L, Markestad T, Davidsen $\mathrm{H}$ et al. Selective ultrasound screening for developmental hip dysplasia: effect on management and late detected cases. A prospective survey during 1999-2006. Paediatr Radiol 2014; 44: 410-424

[80] Leba T, Carmichael K, Patton A et al. Ultrasound for infants at risk for developmental dysplasia of the hip. Orthopedics 2015; 38: e722 - e726

[81] Sanghrajka A, Murnaghan C, Shekkeris A et al. Open reduction for developmental dysplasia of the hip: failures of screening or failures of treatment? The Annals of The Royal College of Surgeons of England 2013; 95: $113-117$

[82] Sink E, Ricciardi B, Torre K et al. Selective ultrasound screening is inadequate to identify patients who present with symptomatic adult acetabular dysplasia. Journal of Children's Orthopaedics 2014; 8: 451-455

[83] Marks D, Clegg J, Al-Chalabi A. Routine ultrasound screening for neonatal hip instability. Can it abolish late-presenting congenital dislocation of the hip? J Bone Joint Surg [Br] 1994; 76-B: 534-538

[84] Clegg J, Bache C, Raut V. Financial justification for routine ultrasound screening of the neonatal hip. J Bone Joint Surg [Br] 1999; 81-B: $852-$ 857 
[85] Wirth T, Stratmann L, Hinrichs F. Evolution of late presenting developmental dysplasia of the hip and associated surgical procedures after 14 years of neonatal ultrasound screening. J Bone Joint Surg [Br] 2004; 86: $585-589$

[86] Von Kries R, Ihme N, Altenhofen L et al. General ultrasound screening reduces the rate of first operative procedures for developmental dysplasia of the hip: a case control study. J Paediatr 2012; 160: 271 - 275

[87] Thalinger C, Pospischill R, Ganger R et al. Long-term results of a nationwide general ultrasound screening system for developlental disorders of the hip: the Austrian hip screening program. J Child Orthop 2014; 8: 3 10

[88] Guler O, Seker A, Mutlu S et al. Results of a universal hip screening program at a single institution. Acta Orthop Traumatol Turc 2016; 50 : 42 48

[89] Munkhuu B, Essig S, Renchinnyam E et al. Incidence and treatment of developmental hip dysplasia in Mongolia: a prospective cohort study. PloS One 2013; 8: e79427. doi:10.1371/journal.pone.0079427

[90] Baumann T, Munkhuu B, Chuluunbaatar B et al. 4-year follow-up of ultrasound-based diagnosis and non-surgical treatment of developmental dysplasia of the hip in Mongolia: a prospective cohort study. Ultraschall in der Medizin - European Journal of Ultrasound 2016; 37 (Suppl. 1): SL3_2

[91] Baumann T, SMOPP-Team. ABCD of DDH. SMOPP/SVUPP. 2017; 1st ed

[92] Ihme N, Altenhofen L, von Kries R et al. Orthopäde SHiD, 3. Sonografisches Hüftscreening in Deutschland. Orthopäde 2008; 37: 541 - 549

[93] Paton R, Hossain S, Eccles K. Eight-year prospective targeted ultrasound screening program for instability and at-risk hip joints in developmental dysplasia of the hip. Journal of Pediatric Orthopaedics 2002; 22: 338 341

[94] Elbourne D, Dezateux C, Arthur R et al. Ultrasonography in the diagnosis and management of developmental hip dysplasia (UK Hip Trial): clinical and economic results of a multicentre randomised controlled trial. Lancet 2002; 360: 2009-2017
[95] Gray A, Elbourne D, Dezateux C et al. Economic evaluation of ultrasonography in the diagnosis and management of developmental hip dysplasia in the United Kingdom and Ireland. J Bone Joint Surg [Br] 2005; 87-A: 2472 - 2479

[96] Thaler M, Biedermann R, Lair J et al. Cost- effectiveness of universal screening compared with clinical examination alone in the diagnosis and treatment of neonatal hip dysplasia in Austria. J Bone Joint Surg [Br] 2011; 93-B: $1126-1130$

[97] Graf R, Mohajer M, Plattner F. Hip sonography update. Quality management, catastrophes - tips and tricks. Med Ultrason 2013; 15: 299 303

[98] Biedermann R, Eastwood D. Universal or selective ultrasound screening for developmental dysplasia of the hip? A discussion of the key isues. J Child Orthop 2018; 12: 296-301

[99] Laborie L, Engesaeter I, Lehmann T et al. Screening strategies for hip dysplasia: long term outcome of a randomised controlled trial. Pediatrics 2013; 132: $492-501$

[100] Pavlik A. The functional method of treatment using a harness with stirrups as the primary method of conservative therapy for infants with congenital dislodation of the hip. Clin Orthop Relat Res 1957; 1992: 4 10

[101] Cashman J, Round J, Taylor G et al. The natural history of developmental dysplasia of the hip after early supervised treatment in the Pavlik harness. A prospective longitudinal follow-up. J Bone Joint Surg [Br] 2002; 84: $418-425$

[102] Murnaghan M, Browne R, Sucato D et al. Femoral nerve palsy in Pavlik harness treatment for developmental dysplasia of the hip. J Bone Joint Surg Am 2011; 93: 493-499

[103] Lauge-Pedersen H, Gustafsson J, Hagglund G. 6 weeks with the Von Rosen splint is sufficient treatment of neonatal hip instability. Acta Orthopaedics 2006; 77: 257-261

[104] Kilsic P. Congenital dislocation of the hip: a misleading term. J Bone Joint Surg 1984; 71B: 136

[105] Talbot C, Paton R. Screening of selected risk factors in developmental dysplasia of the hip: an observational study. Arch Dis Child 2013; 98: $692-696$ 